\title{
Las cautivas de la casa real de Troya: Casandra y Polixena
}

\author{
Nazira Álvarez Espinoza \\ Escuela de Filología, Lingüística y Literatura \\ Universidad de Costa Rica
}

\begin{abstract}
Resumen
El presente trabajo analiza las relaciones de género presentes en las tragedias de Eurípides Troyanas y Hécuba en relación con la violación, el sacrificio ritual, la violencia física, sexual y simbólica que experimentan las cautivas reales de Troya Polixena y Casandra al enfrentar su destino como esclavas después de la Guerra de Troya.
\end{abstract}

Palabras claves: género, violencia simbólica, Polixena, Casandra, Eurípides, violación, sacrificio ritual, mujeres, esclavitud

\section{Abstract}

This paper analyzes gender relations in Euripide's tragedies The Trojan Women and Hecuba regarding rape, ritual sacrifice and physical, sexual and symbolic violence against the royal captives Polixena and Kassandra as they both face their destiny as slaves after the Troyan war.

Key words: gender, symbolic violence, Polixena, Kassandra, Euripides, rape, ritual sacrifice, women, slavery

$\mathrm{L}$ a violencia física, sexual y simbólica ejercida sobre la identidad femenina ${ }^{1}$, a partir del estudio de las relaciones de poder y de la perspectiva de género ${ }^{2}$, señala la perpetuación del orden patriarcal construido desde la imposición, el orden simbólico y la legitimación del poder. La importancia de comprender la vigencia del fenómeno de la violencia contra las mujeres exige volver la mirada hacia los textos literarios para conocer cómo la cultura ha legitimado la violencia de género durante siglos. 
El análisis de la violencia contra las mujeres es un fenómeno reciente; sin embargo, los antecedentes se remontan desde la antigüedad. El análisis de la violencia simbólica contra las mujeres en los textos del mundo antiguo contribuye a identificar y visibilizar conductas que se han aceptado como normales en función de una cultura occidental donde las "ciudadanías femeninas" fueron inexistentes a lo largo de la historia.

En la Grecia antigua, la violencia contra las mujeres era considerada normal, en la medida en que no era conceptualizada como tal dentro del contexto y de la ideología de la época. La importancia de conocer los orígenes de las percepciones de la violencia, en relación con lo femenino y lo masculino en el imaginario social griego, permite identificar conductas desde la marginalidad actual en relación con el tema de la violencia contra las mujeres.

La necesidad de no aislar el estudio de esta categoría en la actualidad abre el espacio para investigar el origen y la justificación de la violencia ejercida contra los personajes femeninos en la literatura. Una aproximación a partir del análisis del fenómeno de la violencia, como parte de las desigualdades de género en las relaciones sociales y de la devaluación de lo femenino, hace posible visualizar el fenómeno en función de las jerarquías y el ejercicio del poder:

... Todo sistema de dominación se compone de dos elementos, su estructura y su ideología. El componente de la estructura se manifiesta en la organización jerárquica de las instituciones y de las relaciones sociales. La ideología es el medio de apoyo del principio del orden jerárquico: es la racionalización de la desigualdad. (Sagot, 1995, p. 59)

El mundo sexualmente jerarquizado induce a las mujeres a un silenciamiento e invisibilización reflejados en la aceptación de un sistema de prohibiciones y prescripciones arbitrarias. La violencia de género ${ }^{3}$ se encuentra posicionada en la base ideológica simbólica fundacional del patriarcado, cuya vigencia como sistema institucional de la sociedad se mantiene hasta nuestros días. En este sentido, como bien señala Scott (1990), el género facilita un modo de decodificar el significado y de comprender las complejas conexiones entre varias formas de interacción humana (p. 13). La violencia simbólica de la cultura patriarcal presente en los textos literarios denota la existencia de una ideología transmitida por medio de la problemática social y el ejercicio del poder. Braidotti (2000) asevera que el género dentro de la teoría feminista tiene la función de enfrentar la tendencia universalista del lenguaje crítico, la cual tiende a "combinar el punto de vista masculino con el punto de vista general, humano, y confinar, por lo tanto, lo femenino, a la posición estructural de lo otro" (p. 174).

En las Troyanas y la Hécuba de Eurípides no solo se presenta la violencia física de la esclavitud de los vencidos, sino una violencia sexual y simbólica que las mujeres aceptan como natural. Es importante señalar que la esclavitud usualmente se ha analizado en función de las mujeres de clase aristocrática convertidas en esclavas (Scodel, 1998). El objetivo del presente trabajo se centra en 
el análisis de las cautivas de la casa real de Ilión y la violencia contra las mujeres presente en la tragedia de las Troyanas.

El artículo se inicia con las definiciones actuales sobre la violencia contra las mujeres. En un segundo apartado se contextualiza la esclavitud, la violación y el sacrificio en la Grecia arcaica. El tercer apartado analiza las manifestaciones, expresiones y formas de la violencia (sexual, física y simbólica). Finalmente, se analiza la violencia simbólica presente en los personajes de Casandra y Polixena después de la caída de Troya.

\section{Violencia contra las mujeres}

Existen diferentes taxonomías del concepto violencia que Pinker (2012) categoriza adaptando el esquema de Baumeister (1997). El autor afirma que las raíces de la violencia se encuentran en cinco ejes fundamentales. En primer lugar, la práctica, instrumental, explotadora o depredadora de los actores sociales; esta violencia es la más sencilla ya que hace uso de la fuerza para conseguir el fin (codicia, lujuria, ambición, otros); una segunda raíz de la violencia la constituye la dominación (la búsqueda de supremacía sobre los otros); una tercera fuente es la venganza (furia y miedo); la cuarta, el sadismo (placer de causar daño); y por último, la ideología (motivos relacionados con un credo, en ella se recluta a otros para que realicen sus fines destructivos) (Pinker, 2012).

En el discurso oficial, el lenguaje incorpora los sentidos y referentes sociales, los mandatos y el orden que impone una conducta que determina lo que se debe hacer, ser y decir para formar parte de la colectividad. Scott (1990) presenta una definición de género en la que establece la conexión integral entre dos proposiciones: el género es un elemento constitutivo de las relaciones sociales basadas en las diferencias que distinguen cada sexo: y el género es una forma primaria de relaciones significantes de poder (Scott, 1990, p. 11). Además, la autora incluye una distinción de cuatro elementos fundamentales en la definición de las relaciones de género: primero, los símbolos culturalmente disponibles que evocan representaciones múltiples; segundo, los conceptos normativos que manifiestan las interpretaciones de los significados de los símbolos, las nociones políticas y referencias a las instituciones y organizaciones sociales; tercero, las relaciones de género; y finalmente, un cuarto aspecto que es el de la identidad subjetiva. Los seres humanos viven atravesados por su condición de género en relación con la forma cómo expresan la subjetividad individual en función del acceso y posibilidades de acción, prácticas cotidianas en relación con los recursos simbólicos y materiales.

Al hablar de la violencia de género no se excluyen las diferentes identidades sexuales. La imagen social del cuerpo, con la que cada agente tiene que contar, desde muy temprano, se obtiene mediante la aplicación de una taxonomía social cuyo principio coincide con el de los cuerpos a los que se aplica (Bordieu, 2000). En este sentido, como apunta Buttler (2005), "la femineidad no es producto de una decisión sino de la cita obligada de una norma, una cita cuya compleja 
historicidad no puede disociarse de las relaciones de disciplina, regulación y castigo" (p. 326).

En las diferentes culturas antiguas, la oposición binaria hombre/mujer contiene, como afirma Lamas, los tres registros de la experiencia humana que Lacan propone: lo simbólico, lo imaginario y lo real. En este contexto, según la autora: "La cultura marca a los seres humanos con el género y el género marca la percepción de todo lo demás, lo social, lo político lo religioso y lo cotidiano" (Lamas, 2000, pp. 344-345).

En la división arbitraria de la construcción de los sexos, se presenta una legitimidad y normatividad que se insertan en el sistema de estructuras cognitivas y estructuras sociales donde mediante el papel asignado por la sociedad, un individuo es valorado e incluso juzgado por la colectividad en relación con la concordancia de sus acciones según la normatividad establecida (Bordieu, 2000). La violencia contra las mujeres desde los ejes corporales, psicológicos y simbólicos es definida por la Declaración de Beijing como:

113. La expresión "violencia contra la mujer" se refiere a todo acto de violencia basado en el género que tiene como resultado posible o real un daño físico, sexual o psicológico, incluidas las amenazas, la coerción o la privación arbitraria de la libertad, ya sea que ocurra en la vida pública o en la privada.

114. Entre otros actos de violencia contra la mujer cabe señalar las violaciones de los derechos humanos de la mujer en situaciones de conflicto armado, en particular los asesinatos, las violaciones sistemáticas, la esclavitud sexual y los embarazos forzados. (O.N.U., 1995, pp. 51-52)

El ejercicio de la violencia ${ }^{4}$ en contra de las mujeres ha prevalecido bajo diferentes manifestaciones temporales, espaciales y geográficas, así como bajo diferentes modalidades. Las violencias física, psicológica y simbólica son manifestaciones del fenómeno citado desde diversas aproximaciones que con frecuencia se entrecruzan y se combinan en el ejercicio del dominio y la sujeción masculina contra las mujeres.

\section{La violencia simbólica}

La violencia simbólica incluye no solo los aspectos físicos, sexuales o psicológicos, sino otros tipos de relación, en los cuales la violencia se transforma en una subordinación femenina dentro de un orden simbólico cultural considerado como normal e internalizado. De manera que es posible considerar la forma como:

Las características generales de la violencia simbólica ejercida sobre el género femenino, definen el entretejido de los diferentes órdenes socioculturales que convergen en los patrones de representaciones simbólicas que 
imponen, producen o garantizan la socialización de un "deber ser/hacer sociocultural” según el género. (Aguilar, 2002, p. 165)

Para Bordieu (2000), la violencia implícita o invisible, que él denomina simbólica, tiene su fundamento en las estructuras de dominación que desvalorizan lo femenino al menospreciarlo. Por esta razón, señala el autor, las mujeres aceptan la dominación masculina como un hecho natural ligado a la biología que:

transforma en naturales aquellas modalidades culturales que tienen por finalidad someter un determinado grupo social, utilizando estrategias que han sido desarrolladas por aquellos que tienen el poder. Es decir, es una violencia que convierte en natural lo que es una práctica de desigualdad social y, precisamente por ello, es una violencia contra la cual suele oponerse poca resistencia. (Bordieu, 2000, p.58)

La violencia ejercida a partir de lo simbólico sirve para degradar, intimidar, manipular y desvalorizar el respeto y la identidad personal de los individuos. Los textos literarios no constituyen por sí mismos un elemento histórico; no obstante, en ocasiones presentan las percepciones de género y la ideología en un contexto espacial y temporal determinado. $\mathrm{Al}$ respecto, como asevera Foucault:

las relaciones de poder son a la vez intencionales y no subjetivas. $\mathrm{Si}$, de hecho, son inteligibles, no se debe a que sean el efecto, en términos de causalidad, de una instancia distinta que las "explicaría", sino a que están atravesadas de parte a parte por un cálculo: no hay poder que se ejerza sin una serie de miras y objetivos. $(1977$, p. 56)

El estudio de la representación de los personajes femeninos en los textos del mundo antiguo contribuye a identificar conductas que se han aceptado como normales en función de una cultura occidental en la cual las "ciudadanías femeninas" (Vargas, 2002) fueron inexistentes a lo largo de la historia. Para Vargas (2002), la importancia de combinar la dimensión política y la dimensión social de las ciudadanías femeninas, con el fin de unir la justicia social y la justicia de género, es fundamental para la subversión cultural y la subjetividad como estrategias de transformación. Por esta razón considera que:

Esta mirada hacia lo político cultural impulsa nuevas interrogantes frente a nuestras las luchas históricas como la de la violencia contra la mujer, que hoy por hoy parece encontrar su límite más claro justamente en esta cultura autoritaria dese el Estado sino también desde la sociedad civil. (Vargas, 2002, p. 10)

El "sexo", entendido como la base material o natural para determinar la imposición de género, como un concepto sociológico o cultural, se encuentra determinado por un sistema social en el que las categorías mujer y hombre se 
encuentran asociadas al "sexo biológico" considerado como natural dentro de la lógica binaria del género. Lo anterior hace que lo "aparentemente biológico" y los efectos reales que se constatan en los cuerpos y las mentes sean resultado de un largo periodo de socialización colectiva. Así, es entendible que:

Las mismas mujeres aplican a cualquier realidad y, en especial, a las relaciones de poder en las que están atrapadas, unos esquemas mentales que son el producto de la asimilación de estas relaciones de poder y que se explican en las oposiciones fundadoras del orden simbólico. Se deduce de ahí que sus actos de conocimiento son, por la misma razón, unos actos de reconocimiento práctico, de adhesión dóxica, creencia que no tiene que pensarse ni afirmarse como tal, y que "crea" de algún modo la violencia simbólica que ella misma sufre. (Bordieu, 2000, p. 49)

Una consecuencia de este proceso es la forma cómo se conjugan las causas y los efectos para presentar una construcción social naturalizada (Bordieu, 2000). Esta última aparece como natural para el autor y, por lo tanto, señala que la división del género es arbitraria en el principio de la representación de la realidad.

La caracterización de la violencia simbólica se manifiesta por medio de la imposición, el orden, la legitimación, la valorización, el poder, el privilegio, la dominación y la sanción desde lo simbólico como percepción de la subordinación andrologocéntrica (Aguilar, 2002).

El hombre y la mujer pueden ser leídos como actuaciones culturales, que constituyen su aparente "naturalidad" mediante actos performativos discursivamente restringidos que producen el cuerpo a través de las categorías de sexo y dentro de ellas. (Buttler, 2001, p. 28)

La valorización de las acciones paradigmáticas señala como positivo, en el ámbito sociocultural, lo masculino y lo femenino como disvalor desde una jerarquía de dualidades, donde lo femenino es considerado como inferior (Aguilar, 2002). La autora señala que el poder simbólico es el instrumento que hace posible el dominio sobre las mujeres por medio de las imágenes de las representaciones y significados sociales que legitiman lo masculino.

Aguilar (2002) indica que el privilegio simbólico es otorgado por la potestad, asociada desde la dominación andrologocéntrica arbitraria en el ejercicio del poder, de forma totalitaria e impositiva "que supedita y controla lo femenino o lo feminizante desde lo masculino/masculinizante. Esta práctica se apropia de los valores, significados, símbolo, bienes y representaciones, definiéndolos desde una lógica masculina y excluyendo el género femenino" (2002, p. 186). Finalmente, para la autora, la sanción simbólica es la forma cómo se hace pública y explícita la desvalorización por medio de la moral que deslegitima lo femenino desde el orden hegemónico patriarcal. Lo anterior resulta evidente en el mundo antiguo griego, las mujeres, como consecuencia de la guerra, se convierten en objetos de intercambio y sufren el ejercicio de la violencia al ser esclavas. Esta sujeción va 
más allá de la corporeidad inmediata, con la cual se instaura una violencia simbólica que las obliga a aceptar su objetivación.

\section{La esclavitud y la violencia contra las mujeres en el mundo griego}

En la Grecia aracaica, las mujeres pertenecían al varón como propiedad. El valor asignado a las mujeres en el sistema patriarcal griego las considera como objeto de intercambio entre los hombres ${ }^{5}$. Bordieu (2000) señala que el orden social masculino se encuentra insaturado, por lo que no necesita una justificación ya que se impone como autoevidente y es aceptado como natural por el acuerdo de las estructuras sociales (organización social de espacio y tiempo, división sexual del trabajo) y las estructuras cognitivas (el cuerpo y la mente). Si bien es cierto que los personajes femeninos en la tragedia ática constituyen construcciones del imaginario griego presentes en los diversos discursos que lo caracterizan:

But Attic drama should not be understood simply as univocal, hegemonic discourse in service of civic ideology; it is a complex, polyvocal, and polysemous genre that alternatively subverts and reinforces the dominant agenda. (McLure, 1999, p. 5)

La legitimación del sistema que autoriza la masculinidad hegemónica y el dominio masculino sobre las mujeres es aceptada como natural en diversas culturas, en las cuales se asumen a las mujeres como seres inferiores propiedad de los varones.

En Atenas, la marginación de las mujeres de la ciudadanía explica la escasa presencia, en los textos escritos, del término polites para denominar a las atenienses. En su lugar se emplea el término asté , que significa que la mujer era integrante de la comunidad cívica solamente a través de la sangre, el parentesco y el culto. (Molas, 2006, p. 97)

La escasez de evidencia e información sobre la vida de las mujeres griegas se encuentra en relación con la invisibilidad que las caracterizaba. Aisladas de la esfera pública y recluidas la mayor parte del tiempo en el hogar, las mujeres atenienses se definían en función de sus parientes masculinos y como tal su estatus era un reflejo de ellos. La condición de dependencia y subordinación estaba ligada a su condición legislativa como menor de edad permanente:

Athenian law of all periods tended to regard the wife as veritable child, having the legal status of a minor in comparison to her husband. Although males came of age at eighteen, females never did. (Pomeroy, 1976, p. 74)

Las mujeres se encontraban sujetas al control masculino desde su infancia. El kyrios, en su función de padre, esposo, abuelo, hijo, tío o tutor legal tenía potestad de decidir sobre las mujeres de la familia o el Estado. 
The Athenians may have invented democracy, but they gave the vote neither to women nor to slaves. An obvious consequence of this sort of social system was, from a feminist standpoint, the abiding predisposition of mythmakers, poets and philosophers to justify the status quo in which women are subjugated and regarded as both dangerous and inferior, whose sexual subjectivity must be rigidly controlled in order to sustain a social system based on the exchange of women. (Peradotto \& Sullivan, 1984, p. 2)

El estatus de las mujeres en la sociedad griega estaba condicionado por su clase social, sus relaciones familiares, su etnia y su condición legal:

La distinción entre una mujer casada y libre y una esclava quedaba expresada por los diferentes grados de libertad. La diferencia de clase entre una esposa que vivía bajo el dominio o la protección del marido y una esclava que vivía bajo el dominio o la protección del amo era principalmente que la esposa podía poseer esclavos, varones o mujeres, y otras propiedades. (...) La jerarquización entre los hombres partía de las relaciones de propiedad e iba reforzada por la fuerza militar. (Lerner, 1990, p. 151)

La guerra, como expresión de violencia a través de la historia, causa no solo la muerte sino que afecta en los ámbitos social, cultural e individual de los pueblos que la sufren. En este sentido, como bien señala el historiador Jenofonte en la Ciropedia, " es una ley eterna en todo el mundo, que cuando una ciudad es tomada en la guerra, los ciudadanos, las personas y todas sus propiedades caen en las manos de los conquistadores" (Jenofonte, 1987). En el orden simbólico patriarcal del mundo griego antiguo, la violencia se erigió como la forma ideal de resolver los conflictos, en especial con la idea de enfrentar la civilización a la barbarie, ajena a los ideales racionales del mundo helénico. En este contexto, si bien todos los participantes pagaban un alto precio, los débiles y sometidos eran quienes sufrían las consecuencias más graves de tales enfrentamientos. Así, las mujeres, consideradas como ciudadanas de segunda categoría y sometidas a los varones, soportaban el yugo opresor con mayor dureza por su condición:

En el contexto de los conflictos bélicos, la violencia que las mujeres padecen tiene connotaciones específicas, pues además de soportar los desastres, desgracias y sufrimientos que las guerras provocan sobre la sociedad en su conjunto, las niñas y las mujeres sufren las agresiones sexuales de los hombres -y no solo de los enemigos- por haber nacido en un cuerpo sexuado femenino. (Molas, 2006, p. 56)

Durante las guerras, como bien lo señala la Ilíada, las mujeres se convertían en botín de guerra del vencedor. Independientemente del estatus que hubiesen tenido en su vida anterior, al ser vencidos sus representantes masculinos, ellas perdían todo derecho y se convertían en un objeto ${ }^{6}$. 
En el caso de las mujeres, su lugar dentro de la jerarquía estaba mediatizado por el estatus de los varones de quienes dependían. Abajo de todo se encontraba la esclava, de cuya sexualidad disponían los hombres poderosos como si de una mercancía comerciable se tratara; en el medio, la concubina esclava, cuyas prestaciones sexuales podían suponerle un acceso en la escala social, la concesión de algunos privilegios y la obtención de derechos hereditarios para sus hijos. (Lerner, 1990, p. 151)

En la Ifigenia en Aúlide, Eurípides afirma: "es justo que los griegos manden sobre los bárbaros" (vv.1400). Al respecto, como señala Said (1990), desde la época homérica ya se demarca Oriente y Occidente en los textos de Esquilo y Eurípides: "Asia habla a través de -y gracias a- la imaginación de Europa" (1990, p. 82). Ya desde entonces, como bien señala el autor, se piensa en ese "otro" como el mundo hostil, territorio de bárbaros que se encuentra fijado por la imaginaria de Europa. Oriente y su misterio en la mente occidental supone para Said (1990) "un desafío para la mente racional occidental". Y en función de relaciones de poder, se encuentra la necesidad de Occidente de subyugar, vencer y someter a Oriente: argumento que Aristóteles incluirá en la Política para asimilar el origen natural del bárbaro con la esclavitud.

En la Política, Aristóteles afirma que entre los bárbaros, hembra y esclavo tienen la misma categoría (I,3,1.253,b y II-1252,a-1252,b). En relación con el uso de la violencia y la esclavitud, Eurípides en las Fenicias reafirma ideas ya señaladas con anterioridad ante la toma de una ciudad: "verás a esta ciudadela tebana sometida, verás a muchas doncellas cautivas ultrajadas con brutalidad por los guerreros enemigos" (vv.563.565). El Estagirita, en la Política, señala el origen natural de la esclavitud y cómo uno de los objetivos de la guerra es convertir en esclavos a aquellos que lo merecen; de esta forma, justifica la esclavitud de los bárbaros. El panorama de la esclavitud femenina no solo aparece en los textos de autores clásicos, sino en registros anteriores como las tablillas micénicas:

The picture given by Homer is confirmed by Mycenaean tablets listing large numbers of women and children, sometimes with their places of origin. The women and children are probably slaves and males are recorded as sons of the women, indicating that they were born in an informal union. (Pomeroy, 1976, p. 26)

En la guerra, las mujeres constituyen objetos pasivos, siempre sujetas al destino de los varones. Ellas serán premio y botín de guerra, reconocimiento para el honor y la gloria masculina. Homero enfatiza en la Ilíada, la suerte de las cautivas de guerra cuando Héctor se reúne con su esposa Andrómaca frente a las puertas Esceas:

Mas no me importa tanto el dolor de los troyanos en el futuro ni el de la propia Hécuba ni el del soberano Príamo ni el de mis hermanos, que, muchos y valerosos, puede que caigan en el polvo bajo los enemigos, como el tuyo, 
cuando uno de los aqueos, de broncíneas túnicas, te lleve envuelta en lágrimas y te prive de la libertad, y luego tejas telas en Argos, a las órdenes de otra mujer, o vayas por agua a la fuente Meseida o Hiperea, muy contrariada, porque la dura necesidad pesará sobre ti. (Homero, Ilíada, VI, 450-459)

Las cautivas troyanas no tienen patria, familia ni rango; una vez arrasada la ciudad de Ilión se convierten en botín y, por lo tanto, se objetivizan y pierden cualquier derecho obtenido en función del rango que ostentaban gracias a las relaciones que mantenían con los varones de Troya. La violación, el rapto y la esclavitud no son considerados como violencia contra las mujeres sino como acciones necesarias al vencer a un pueblo. En relación con la esclavitud de los siglos IX y X a.C., Finley comenta:

Los esclavos existían en gran número; eran propiedades que se podía disponer a voluntad. Para ser más exactos, existían esclavas, ya que la principal fuente de suministro eran las guerras o las incursiones y no tenían muchos motivos, de orden económico o moral, para perdonar la vida a los hombres derrotados. Por norma, los héroes mataban a los varones y se llevaban a las mujeres fuera cual fuese su rango. (Finley, 1978, p. 63)

El fin de la Guerra de Troya, no solo significó la destrucción de la ciudad de Ilión y sus héroes, sino que inició un nuevo ciclo de dolor para las mujeres reales de Troya al convertirse en cautivas de los helenos. En estas circunstancias, el destino de las cautivas era determinado por su nuevo amo; podían ser violadas, convertidas en esclavas, concubinas, sacrificadas o asesinadas.

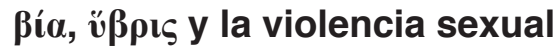

A lo largo de la historia, la violencia sexual no ha despertado siempre la misma respuesta jurídica, ni ha sido igual la sensibilidad o los criterios con que se le ha valorado. La violación de un cuerpo ha provocado sufrimiento, humillación, temor, dolor y dominación por la fuerza. La diferencia radica en las actitudes mentales que enmascaran, o no, el sometimiento del cuerpo del otro mediante la fuerza y el terror y en el caso de las mujeres, esas actitudes mentales varían dependiendo de los sistemas de opresión ejercidos sobre ellas (Molas, 2006, p. 49). En este sentido, es importante recordar: "Rape is easy to distinguish when the victim has the possibility of protection by someone other than the rapist and no continuing relationship is created, but captured women remain with the men who have taken them" (Scodel, 1998, p. 138).

La violación ${ }^{7}$ en el mundo griego antiguo se convierte en un elemento aceptado como prerrogativa de los vencedores en la guerra. La violación socialmente tenía dos elementos centrales para ser considerada como tal: el empleo de la fuerza y el asalto. No obstante, en tiempos de guerra no existía una sanción social, pues era lo esperado en el orden cultural establecido: 
The words $\beta$ í $\alpha$ and $\ddot{\beta} \rho ı \varsigma$ (the terms specifically used in lawsuits to refer to

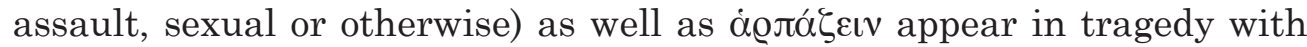
sexual meaning. (...) These words do not denote sexual penetration per se:

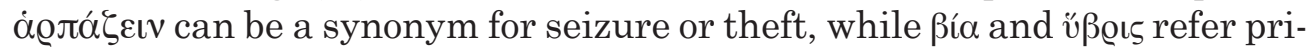
marily to violence. The sexual content must generally be inferred from the context. Lack of consent, as opposed to physical violence, can be seen in the language of willing vs. unwilling sexual encounter. (Rabinowitz, 2011, p. 8)

En la literatura, la Iliada reafirma la idea cuando Néstor impulsa a los guerreros helenos al combate y les recuerda: "Por eso, que nadie se apresure a regresar aún a casa antes de acostarse con la esposa de alguno de los troyanos y cobrarse venganza por la brega y los llantos de Helena" (Homero, Il.vv. 354-356). De esta forma, afirma la idea de posesión y objetivación sobre las mujeres como botín de guerra. El orador Esquines, también confirma la idea del sometimiento no deseado, implícito en la violación, al prohibir el uso de la fuerza (ßía) y la hybris (üßpı) (Esquines, 1.15-17 2002).

\section{El sacrificio ritual y la violencia física}

El relato del primer sacrificio ritual ofrendado a las divinidades se encuentra narrado en la Teogonía de Hesíodo (vv. 540-555) al relatar cómo hombres y dioses separaron su vida en común. El primer sacrificio relatado en la literatura correspondió a un sacrificio cruento, el sacrificio ritual de un animal para ofrendar a los dioses. Los sacrificios para las divinidades pueden ser cruentos o incruentos. Estos últimos usualmente comprenden el sacrificio de animales. En textos como la Ilíada y el teatro griego se alude a víctimas humanas sacrificiales. En el caso de las mujeres, usualmente son doncellas:

En el caso de las Tragedias de Eurípides, éstas reflejan una tipología de víctima concreta cuya caracterización puede resumirse en dos aspectos fundamentales: la virginidad y el linaje. Ambos elementos hacen de determinadas personas un phármacos ideal, sobre el que la sociedad desplaza su violencia y, gracias al cual, se pone fin a la crisis, propiciándose el orden y el restablecimiento de la armonía. (Rubiera, 2011, p. 115) ${ }^{8}$

La necesidad del sacrificio usualmente surge ante acontecimientos bélicos, donde el sacrificio humano tiene como fin honrar y apaciguar la ira de una divinidad, o para glorificar y rendir cultos funerarios para un héroe caído en la guerra. En la Ilíada, Aquiles menciona el funeral de Patroclo y señala que sacrificará a doce nobles troyanos ante la tumba de su amigo. El sacrificio de una doncella en el entorno bélico aparece en el mito de la Guerra de Troya, ligado en la casa de Atreo, antes de partir hacia Ilión.

La muerte de una joven doncella puede traer gloria y honor para ella y su familia si son aceptados con valor y entereza. En virtud de un sacrificio impuesto 
por el orden social, surge una legitimación del sacrificio ritual para honrar a una divinidad o a un héroe muerto. El poder de la comunidad posee el privilegio andrologocéntrico para dominar y someter lo femenino, cuya valoración se encuentra en función de las necesidades sociales y culturales.

En la tragedia griega del siglo V a.C. aparecen en escena sacrificios humanos, en la que a pesar de una reticencia inicial de la comunidad, se presentan sacrificios decretados por la divinidad, por medio de oráculos o también de $\varphi \alpha ́ \sigma \mu \alpha \imath$ que solicitan el sacrificio de una víctima en su tumba. En este punto es importante resaltar:

At a time when politics and religion were one in the same, sacrifice was crucial in regulating governmental issues. Tragedies manipulate rituals in order to portray a community's current sense of order or disorder. The pattern of sacrifice typically entails conflict between the needs of an individual and those of a community in crisis, ultimately resolved in favor of the community through willing participation of the sacrificial victim. (Easterling, 1997, p. 188)

Las "vírgenes sacrificiales" en Eurípides tienen dos cualidades fundamentales: son doncellas sin mácula y poseen sangre real; son las nymphe parthenos. El matrimonio tradicional es sustituido por el sacrificio ritual, una unión con el Hades:

(...) sacrifices in tragedy illuminate the customary ritual in marriage whereby the virgin passes from one kyrios (guardian) to another, from the father who "gives her away" to the bridegroom, who "leads her off". (...) They are weddings in reverse in that they lead toward a sacrificer. (Loureaux, 1991, pp. 36-37)

El sacrificio ritual en el contexto griego no es considerado como violencia; es innegable que se disfraza bajo un elemento religioso visto desde lo privado. Desde la antigüedad, la subordinación de las mujeres a los varones es un fenómeno que ha ido más allá de la inferioridad femenina. Ha trascendido lo racional, convierte en objetos a las mujeres y manifesta la dominación en comportamientos agresivos legitimados por el patriarcado y ratificados por las sociedades en los diferentes espacios y contextos históricos y culturales.

\section{Las doncellas reales de llión y la violencia simbólica}

La imposición simbólica surge a partir de la dominación, fruto de la construcción de las representaciones desde lo simbólico cultural subordinado y predefinido como femenino limitado, delimitado y condicionado por medio de la aceptación cultural y social (Aguilar, 2002). El análisis de los personajes femeninos en las tragedias de Eurípides las Troyanas y Hécuba muestra cómo después de 
la caída de Ilión, las mujeres de la casa real son convertidas en cautivas que esperan el sorteo de su destino a manos de sus captores. En diferentes momentos el coro de troyanas expresa temor, dolor y resignación ante su destino incierto como esclavas de los helenos:

El terror ha atravesado el pecho de las troyanas, que, dentro de esta casa, lamentan su esclavitud. (Troyanas vv. 155-160).

¡Ay, ay! ¡Desdichadas troyanas que vais a someteros al trabajo de esclavas, salid de esta mansión! Los argivos preparan el regreso. (Troyanas, vv. 165-170).

¡Ay! ¡Ay! ¡Que mala es siempre por naturaleza la esclavitud, y cómo soporta lo que no debe, sometida por naturaleza. (Hécuba, vv.331)

La violencia contra las mujeres cautivas es explícita e implícita. Las cautivas, en tiempos de guerra, deben aceptar pasiva y sumisamente el destino que los vencedores les impongan ${ }^{9}$. En especial, la unión sexual forzada resulta inherente a su nueva condición y debe ser aceptada de forma complaciente: "In these Trojan war plays, then, rape is explicitly a factor. Violence and üßoıs, as well as the women's unwillingness, are clear indicators of what counts as rape" (Rabinowitz, 2011, p. 14). Por otra parte, también el sacrificio ritual constituye uno de los elementos que aparecen en las tragedias como resultado del conflicto bélico.

\section{Casandra la ménade concubina}

Al inicio de la tragedia, Poseidón y Atenea comentan sobre los últimos acontecimientos de Troya, en relación con Casandra. Atenea interroga a su tío diciéndole: "¿No sabes que hemos sido ultrajados yo y mi propio templo?"10 (Troyanas, vv.68) y el dios le responde: "Lo sé, Áyax arrastró a Casandra por la fuerza"11 (Troyanas, vv.70). Resulta importante notar que el uso de las palabras

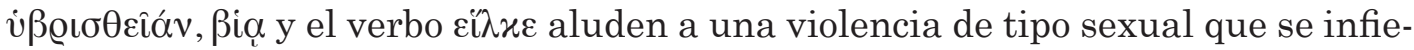
re del contexto. Casandra, de acuerdo con el mito ${ }^{12}$, fue "arrancada" del altar del templo de Atenea por Áyax y violada en el mismo templo.

En el texto, las palabras ßía y üßoıs resaltan la agresión de tipo sexual sufrida por la doncella. Además, el héroe al irrespetar la protección del altar comete una impiedad: "The asylum of the altar stands in polar relation to the shedding of blood; the shedding of human blood constitutes the most extreme, yet dangerously similar contrast to the pious work" (Burkert, 2001, p. 59). De ahí que la diosa se refiera a un "ultraje" cometido en su contra, pues Casandra se había refugiado en el templo como suplicante, no obstante durante la guerra se irrespetan incluso las leyes divinas.

La violencia física y sexual es visible pero la violencia simbólica se manifiesta en la aceptación tácita y la legitimación de los comportamientos en el orden social y cultural, en este caso la esclavitud y las uniones forzadas, a las cuales son obligadas las mujeres cautivas y son aceptadas como naturales: 
El efecto de la dominación simbólica (trátese de etnia, de sexo, de cultura, de lengua, etc.) no se produce en la lógica pura de las conciencias conocedoras, sino a través de los esquemas de percepción, de apreciación y de acción que constituyen los hábitos y que sustentan, antes que las decisiones de la conciencia y de los controles de la voluntad, una relación de conocimiento profundamente oscura para ella misma. (Bourdieu, 2000, pp. 53-54)

El orden simbólico establece, reconoce, distribuye y legitima los privilegios, los poderes, bienes y valores de acuerdo con una construcción patriarcal que se ejerce a partir del ejercicio de una sexualidad diferenciada sobre los cuerpos (Aguilar, 2002). Consecuencia de lo anterior es la legitimación y aceptación del comportamiento sexual masculino en una esfera de acción más amplia y tolerante. La actitud que este orden impone a las mujeres conduce a su objetivación simbólica: "cuerpo como realidad sexuada y como depositario de principios de visión y división sexuantes" (Bourdieu, 1998, p.22). En el caso de Casandra, la virginidad elegida por ella aparece como "recompensa-castigo" impuesta por Apolo, ante el rechazo sufrido por el dios. Al convertirla en pitia debe permanecer virgen, lo cual es irrespetado por los aqueos, primero Áyax y luego Agamenón. Hécuba manifiesta sorpresa ante el irrespeto de los aqueos hacia Casandra: "¿A la virgen consagrada a Febo, a quien el de bucles de oro concedió en recompensa una vida alejada del yugo nupcial?" (Troyanas, vv. 253- 254).

La princesa de Troya es una virgen consagrada a Febo, ultrajada por Áyax

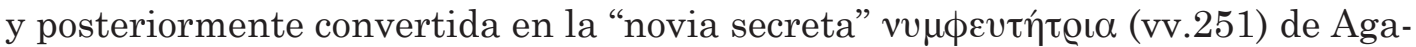
menón: "Cassandra is a virgin priestess, and so stresses the element of violation, and associates her prophetic gift with Dionysiac madness, so that Agamemno's desire seems perverse" (Scodel, 1998, p. 144). El poder simbólico es el que otorga la creencia en el derecho de Agamenón para convertirla en su "compañera" como el privilegio simbólico fundamentado en el derecho político y masculino que posee el atrida para usar a Casandra a su antojo.

En este sentido, Bordieu y Passeron (2004) afirman: "Todo poder de violencia simbólica, o sea, todo poder que logra imponer significaciones e imponerlas como legítimas disimulando las relaciones de fuerza, añade fuerza propia, es decir, propiamente simbólica, a estas relaciones de fuerza" (p. 18). Así, Casandra debe asumir esta unión sin oponer resistencia. Ella en medio de un éxtasis mántico acepta el destino ineludible de una unión forzada, la cual en su caso particular, sustituye el Himeneo tradicional:

¡Oh soberano Himeneo, feliz es el novio y feliz yo que en Argos voy a unirme al lecho de un rey! ¡Himen, oh soberano Himeneo! Porque tú, madre, con lágrimas y sollozos te lamentas de mi padre muerto y de la querida patria, pero yo por mis nupcias levanto la llama del fuego, para brillo, para resplandor para darte, oh Himeneo, para darte, oh Himeneo, luz sobre los tálamos de las vírgenes, como es ritual. (Troyanas, vv.310- 323) 
La madre se lamenta por la forma como se realizan las bodas de su amada hija al señalar la fuerza de la unión; no obstante, la asume como una boda que no es tal: "¡Ay de mí, hija mía! Nunca pensé que llegaras a celebrar tus bodas a punta de lanza y obligada por las armas argivas" (Troyanas, vv.345-348). La manifestación de la violencia simbólica implícita en la sanción pública puede ser realizada por medio de la valoración, la censura, la coacción y las representaciones culturales del lenguaje como medio por el cual se reproducen las instituciones de poder y la jerarquización de los valores de las representaciones simbólicas legitimadas por la autoridad masculina en el orden social.

Las cautivas troyanas reconocen la violencia que se les impone, mas la aceptación que muestran refleja cómo han interiorizado la imposición de una normativa social y cultural que las define como mujeres cuyos cuerpos se convierten en objetos para los guerreros vencedores. Hécuba se lamenta por su hija: "Es terrible la fuerza del destino. Hace poco marchó de mi lado Casandra, arrancada a la fuerza" (Troyanas, vv. 617). Por su parte, Andrómaca afirma el triste destino de su cuñada: "¡Ay, ay! Un segundo Áyax, al parecer, ha surgido para tu hija” (Troyanas, vv. 618), en una clara alusión a una nueva unión forzada:

The difference between rape and a consensual relationship corresponds to a tension within the reason men enslave women (in particular, women of noble origin) in Greek literature. First, women are the enemies' most precious property. Raping them is the final act in defeating their men. (Scodel, 1998, p. 142)

La locura mántica de la princesa, más allá de su condición de bárbara, la convierte en una mujer atemorizante que no respeta las normas establecidas para las mujeres, es calificada por su madre, el coro y el mensajero en diferentes momentos como una ménade. La troyana fue capaz de rechazar incluso la unión con el dios délfico, razón por la cual fue castigada y los vaticinios que emite son ignorados. La valoración negativa del mensajero se dirige a la mujer por su condición y deja de lado la sanción del irrespeto cometido por los aqueos en contra de la sacerdotisa de Apolo:

[...] one of the significant indications of Cassandra's supposed madness would seem to be her "mistaking" her sexual slavery for a legitimate union, calling it "a royal wedding", and "blessed" (311-13); she ends her speech calling her captor "husband" with the unambiguous term róors (340) (Rabinowitz, 2011, p. 15).

La dominación a través de la sanción simbólica hace explícita la desvalorización dentro del orden andrologocéntrico por medio de la apropiación de "valores, significados, símbolos, bienes y representaciones, definiéndolos desde una lógica masculina y excluyendo al género femenino" (Aguilar, 2002, p. 187). Esta dominación por medio de la valoración simbólica se manifiesta en el estigma que recae sobre la pitia de Apolo. El rechazo a la unión sexual del dios se traduce en 
la deslegitimación de su discurso. La veracidad de las palabras oraculares que profiere la princesa de Ilión es descalificada y asociada a la locura. La alegría que ella manifiesta ante la inminente unión con el atrida no es la usual en una cautiva, actitud que la convierte en una representación aún más amenazante:

¡Eleva, ofrece! Porto la luz, venero, ilumino- aquí, aquí- con antorchas el templo. ¡Oh soberano Himeneo, feliz es el novio y feliz yo que en Argos voy a unirme al lecho de un rey! ¡Himen, oh soberano Himeneo! Porque tú, madre, con lágrimas y sollozos te lamentas de mi padre muerto y de la querida patria, pero yo por mis nupcias levanto la llama del fuego, para brillo, para resplandor para darte, oh Himeneo, para darte, oh Himeneo, luz sobre los tálamos de las vírgenes, como es ritual. (Eurípides, Troyanas, vv.309- 323).

Casandra es sometida al poder masculino, a partir de la unión del concubinato, la celebración del himeneo enfatiza el dominio sexual. A Taltibio no le horroriza la impiedad cometida en contra de Casandra, sino el peligro que ella representa; por esa razón, el calificativo de ménade la denigra y la censura. El mensajero del ejército aqueo manifiesta la aversión que siente ante la unión que el rey aqueo realiza con una mujer a la que considera inferior en todo sentido: el gran soberano de los ejércitos de toda Grecia, el amado hijo de Atreo, ha aceptado por su propia elección el amor de esta ménade: "Yo soy un pobre hombre, pero jamás habría querido para mí el lecho de ésta" (Troyanas, vv.414-415). La posesión mántica es también una forma de violencia sobre un cuerpo que se somete por la fuerza. Un pensamiento aracaico que parece prevalecer frente a una Grecia que busca formas más racionales de organización social en el siglo V a.C.. Agamenón se convierte en su nuevo amo, uno al cual no puede rehusar. Esta situación es reafirmada por Hécuba cuando pide la ayuda del caudillo aqueo para atraer a Polímestor al campamento troyano:

Junto a tu costado duerme mi hija, la inspirada por Febo, a la que llaman Casandra los frigios. ¿Dónde demostrarás, señor, que tus noches te son gratas, o qué gracia obtendrá mi hija por sus amabilísimos abrazos en tu cama, y yo por ella? (Hécuba, vv.826-831)

En el caso de Hécuba, muestra resignación ante lo inevitable de la situación y trata de sacar provecho para llevar a cabo su venganza. Si bien el discurso de la anciana resulta un tanto cínico, también debe recordarse que las mujeres cautivas deben aceptar sin protestar los mandatos de los nuevos amos.

Por su parte, Casandra ha sufrido la esclavitud desde su condición real en Troya cuando el dios Apolo la somete a su esfera, al convertirla en su profetisa. El mito relata cómo ella acepta el don del dios y luego se niega a unirse sexualmente a él. Aun así, se convierte en "sierva de Apolo" sometida a la locura mántica desde su juventud y condenada a un silencio a voces como castigo por rechazar al dios. La esclavitud en libertad que vive en Troya es transformada 
en cautiva de los helenos; se convierte en la "novia secreta" del atrida: "In these Trojan war plays, then, rape is explicitly a factor. Violence and úßoıs, as well as the women's unwillingness, are clear indicators of what counts as rape" (Rabinowitz, 2011, p. 16).

La cautiva manifiesta el deseo de unión para ejecutar una venganza, que en el fondo no es ella quien la ejecutará, sino Clitemnestra. Casandra sabe que tendrá un final infame y aún así debe aceptarlo sin resistirse y lo expresa a viva voz:

Que si existe Loxias, el ilustre Agamenón, soberano de los aqueos, va a concentrar conmigo una boda más infausta que la de Helena. Voy a matarlo, voy a destruir su casa para tomar venganza de mis hermanos y padre. Dejaré lo demás: no quiero cantar un himno al hacha que va a caer sobre mi cuello y el de los demás... (Eurípides, Troyanas vv. 357- 361)

... conductor de los Dánaos, recibirás sepultura de mala manera y de noche, no de día. Y en cuanto a mí, me arrojarán desnuda y las torrenteras de nieve fundida entregarán mi cadáver- jel de la sierva de Apolo!- a las fieras para banquete, cerca de la tumba de mi prometido. (Eurípides, Troyanas, vv.446-451)

Al llegar a Micenas, será asesinada junto a su nuevo amo por Clitemnestra. La única elección que en realidad tuvo Casandra fue la de aceptar al dios y al rechazarlo solo escapó de la unión sexual pero quedó sujeta a la posesión mántica; su cuerpo y mente fueron presa del dios delio. Así, ella terminará aceptando como natural su condición, primero como sierva de Apolo y luego como cautiva de los helenos. En este sentido como bien afirma Fraisse (2002):

Primero, la obediencia a una razón de la especie superior a la razón individual: la razón de una mujer no es en sí misma su propio fin, sirve para reconocer mejor en qué su naturaleza, precisamente su cuerpo, predomina sobre su espíritu.

La razón de una mujer tiene como función la de comprender su identidad específica y el plan de la naturaleza donde ella juega su papel. Papel natural que induce a un papel social, y los dos significando que una mujer se somete siempre a una instancia superior a ella misma, a un conjunto que inscribe su individualidad en un todo (p. 79)

Casandra es la hija de Príamo, la hermana de Héctor y París, la sierva de

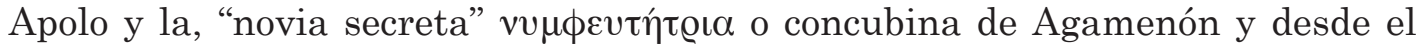
orden y el poder simbólico es objetivizada y valorada en función de estas relaciones. La princesa troyana será sancionada y considerada como presa de la locura mántica, por designio de Apolo. Al rechazar al dios Apolo es castigada y estigmatizada. Al caer Troya pierde su estatus real y es convertida en una esclava. 


\section{Polixena, la virgen sacrificial}

El sacrificio de Polixena es realizado para honrar al máximo héroe de la Hélade, para tal fin debe cumplir con dos requisitos: virginidad y nobleza. La sociedad intenta desviar hacia una víctima relativamente indiferente, una víctima "sacrificable", una violencia que amenaza con herir a sus propios miembros, los que ella pretende proteger a cualquier precio (Girard, 1982, p.12). El phasma de Aquiles se presenta ante los aqueos con la exigencia de una ofrenda acorde con su rango, según lo relata Polidoro:

Todos los aqueos, aquí junto a sus naves, están varados, inactivos, en la costa de esta tierra tracia, pues el hijo de Peleo, Aquiles, apareciéndose por encima de su tumba, ha retenido a todo el ejército heleno, cuando dirigían ellos el remo marino hacia su casa. Reclama a mi hermana Polixena para recibirla como sacrificio grato para su tumba y como honor. (Eurípides, Hécuba, vv.35-42)

Desde el inicio, en un sueño profético, Hécuba presagia el triste y cruel destino que espera a Polixena: "pues he visto una cierva moteada, degollada por la sangrienta zarpa de un lobo, tras haberla arrancado de mi regazo por la fuerza" (Eurípides, Hécuba, vv.90-91), si bien la reina troyana no logra descifrar el significado, muy pronto le será revelado por Odiseo. El héroe es quien le comunica la suerte de la princesa a la reina troyana: "Ha parecido bien a los aqueos degollar a tu hija Polixena junto al empinado túmulo del sepulcro de Aquiles" (Hécuba, vv.219-220).

La madre de la princesa intenta salvarla inútilmente y persuadir a Odiseo diciéndole: “(...) es odioso matar a unas mujeres que no matasteis antes al arrancarlas de los altares, sino las compadecisteis" (Hécuba, vv.290). Incluso, ofrece su vida a cambio de la doncella, suplica que no la sacrifiquen; mas al ver que es imposible, ruega ser sacrificada con ella; más aún, amenaza con enlazarse a ella "como hiedra de una encina" (Hécuba, vv.398 ). En este momento, Polixena asume su destino, se dispone a morir de forma voluntaria, increpa a su madre y se dirige a Odiseo diciéndoles:

Madre tú no seas en nada un obstáculo para nosotros, ni de palabra ni de obra. Exhórtame a morir antes de encontrar un trato vergonzoso en desacuerdo con mi dignidad. (Hécuba, vv.374)

Madre hazme caso. Tú hijo de Laertes perdona a mi madre que está irritada con razón. Y tú, oh desdichada, no luches con los poderosos. ¿Quieres caer al suelo, que desgarren tu viejo cuerpo al apartarte por la fuerza, y perder la compostura al ser arrastrada por un brazo joven, cosas que sufrirás? (Hécuba, vv.404-409 y ss)

La princesa troyana acepta ofrendar su cuerpo a Hades en la tumba de Aquiles ${ }^{13}$, antes que soportar el destino de una cautiva de guerra: "Como esclava 
moriré, aun siendo hija de un padre libre" (Hécuba, vv.420), y para no vivir como tal se entrega al sacrificio: "Aparto de mis ojos libres esta luz, entregando mi cuerpo a Hades. Llévame, pues Ulises y mátame cuando me lleves" (Hécuba, vv.369-370 y ss). El discurso que pronuncia asume el rol que la sociedad ha determinado para ella como mujer sin protección masculina; es tan solo una esclava más:

(...) pero no deploro mi ultraje y afrenta, sino que para mí morir es una suerte mejor. (Hécuba, vv.214)

Porque te voy a seguir de acuerdo con la necesidad, y porque deseo morir. Si no quiero resultaré cobarde y mujer amante de mi vida. ¿Pues por qué debo vivir yo? (Hécuba, vv.346)

Y ahora soy esclava. En primer lugar, el nombre, por no serme habitual, me pone ya en trance de desear morir (...) encontraría yo, quizá las decisiones de un amo cruel...(Hécuba, vv.335 y ss)

(...) un esclavo comprado donde sea ensuciará mi cama, considerada antes digna de reyes. (Hécuba, vv.365 y ss)

Aparto de mis ojos libres esta luz, entregando mi cuerpo a Hades. Llévame, pues Ulises y mátame cuando me lleves. (Hécuba, vv.369-370 y ss)

Sin marido, sin canto nupcial, todo aquello que yo esperaba alcanzar. (Hécuba, vv.416)

Polixena admite que ha padecido ultraje y afrenta; por esa razón, es preferible una muerte honrosa a vivir humillada como esclava de sus enemigos. Al perder su condición real y la protección de los varones de su familia, ha perdido también su valor como mujer y ante tal situación la muerte se presenta como una alternativa viable para escapar del destino infame de su nueva condición. Es importante resaltar que la idea del sacrificio y la objetivación de la princesa se relacionan con los animales (Rodríguez, 2004), los cuales se someten dócilmente. La idea del ritual sacrificial muestra un aspecto relevante de la dominación por la fuerza. El sacrificio y la muerte de la doncella parecen cumplir la función de ritual de paso como lo es el matrimonio ${ }^{14}$. La joven princesa, para evitar la deshonra de ser sujetada por manos de sus captores, acepta morir de forma voluntaria pues no desea ser sujetada y mancillada por manos aqueas:

¡Oh argivos que destruisteis mi ciudad! Moriré voluntaria. Que nadie toque mi cuerpo, pues ofreceré mi cuello con corazón bien dispuesto. Matadme, pero dejadme libre, para que muera libre, por los dioses. Pues siendo una princesa, siento vergüenza de que se me llame esclava entre los muertos. (Eurípides, Hécuba, vv.547-551)

Taltibio relata a Hécuba el valor mostrado por Polixena:

(...) cogiendo el peplo lo rompió desde lo alto de la espalda hasta la mitad del costado, junto al ombligo, mostró los senos y el pecho hermosísimo, 
como de estatua, y poniendo en tierra la rodilla dijo las palabras más valientes de todas: "Mira: golpea aquí, si es que deseas, oh joven, golpear mi pecho y si quieres en la base del cuello, dispuesta está aquí mi garganta». (Hécuba, vv.558-565)

En el sacrificio ritual la palabra sphage literalmente alude al corte sacrificial en la garganta y al flujo de sangre que brota de la herida:

There are sacrificial rituals in which the shedding of blood appears to be carried out for its own sake and not as the prelude to a meal; these are blood sacrifices in the narrower sense, sphagia. They are found primarily in two extreme situations, before battle and at the burial of the dead; the other context in which they occur is at purifications. (Burkert, 2001, p. 60)

Al imponer el sacrificio a la doncella, se espera que se comporte de acuerdo con su linaje. Cuando deciden sujetarla y ella con valor camina a su muerte sin titubear, busca evitar la sanción simbólica y al hacerlo se inscribe dentro de la conducta impuesta a las mujeres de sangre real: "Y ella, aún muriéndose, sin embargo tenía mucho cuidado para caer de buena postura, ocultando lo que hay que ocultar a la mirada de los varones" (Hécuba, vv.569). El discurso oficial incorpora los sentidos y referentes sociales, los mandatos y el orden que imponen una conducta que determina lo que se debe hacer, ser y decir para formar parte de la colectividad. Así, Hécuba acepta los códigos impuestos y se siente orgullosa por la forma como Polixena enfrentó el sacrificio:

Y ahora, yo no podría borrar de mi mente tu sufrimiento hasta el punto de no gemir. Pero me has impedido hacerlo en exceso porque, según me anuncian, te has mostrado noble. (Hécuba, vv.590-592)

(...) el ser educado correctamente comporta, al menos en cierto sentido, una enseñanza de lo bueno. Si uno aprende bien eso, conoce lo deshonroso porque lo ha aprendido con la regla de lo bueno. (Hécuba, vv.601-604)

La doncella troyana no olvida su condición de mujer real y pudorosa, incluso en sus momentos finales. La imagen social del cuerpo, con la que cada agente tiene que contar desde muy temprano, se obtiene mediante la aplicación de una taxonomía social, cuyo principio coincide con el de los cuerpos a los que se le aplica (Bordieu, 2000). Frente al altar, la princesa descubre su pecho para que el sacerdote cumpla con el sacrificio; lo hace sin perder su honor y actúa según la educación correspondiente a su rango. La madre, como se comentó, a pesar del dolor, no puede evitar el orgullo que siente porque su hija mostró valor y discreción hasta el final. Taltibio es quien relata a Hécuba y a las troyanas la ilustre muerte de la princesa, pues ellas no tienen acceso visual al sacrificio de Polixena. La joven se compara con un animal sacrificial antes de morir: 
Ya no conservas a esta hija, ya no seré tu compañera de esclavitud, desgraciada de mí, de una anciana desgraciada. Pues a mí, cachorro tuyo, como a ternera criada en la montaña, infeliz me verás arrancada de tu mano y con la garganta cortada, llevada al Hades bajo las tinieblas de la tierra, donde en compañía de los muertos yaceré infeliz. (Hécuba, vv.200-207)

Polixena, indefensa ante los aqueos, acepta morir dentro de un orden cultural legitimado. Los helenos vencedores en la guerra poseen el privilegio por medio de la dominación andrologocéntrica para disponer de la suerte de las cautivas troyanas. En el sacrificio se visualiza la objetivación de la joven, pues al ser conquistada su ciudad, no solo pierde su estatus sino que es asimilada a un objeto, un animal sacrificial que debe aceptar el destino que los vencedores deciden, lo cual se entiende como natural sin advertir la violencia simbólica implícita en la acción.

El destino de ambas doncellas se encuentra ligado a su condición marginal. Al morir, todos los varones de la familia real quedan a merced del enemigo. Ambas hermanas experimentan el exterminio de la casa troyana, la devastación de Ilión y el sometimiento como cautivas. Frente a la racionalidad Occidental de la cultura griega, ellas son consideradas como la "otredad" que caracteriza Oriente. Polixena y Casandra se convierten en una corporeidad, objetivada por su condición de mujeres indefensas, bárbaras y esclavizadas. Las princesas de Troya morirán a manos de sus captores, Polixena sacrificada, en el Quersoneso, para honrar a un héroe muerto, y Casandra asesinada en Micenas a manos de la esposa de Agamenón, Clitemnestra, para vengar la muerte de su hija Ifigenia, otra víctima sacrificial de los Helenos y la Guerra de Troya.

\section{Conclusiones}

En la cuna de la democracia, se escenifica la legitimación del orden y las jerarquías sociales. Los personajes de la tragedia ática Polixena y Casandra responden a coordinadas temporales y espaciales en un contexto histórico preciso, la Grecia del siglo V a.C., considerada la época de máximo esplendor. Los derechos civiles y políticos de las mujeres se encontraban sujetos a las relaciones de poder. Los valores puestos en escena en relación con la guerra y el destino de los derrotados están vigentes en un periodo histórico caracterizado por guerras intermitentes y continuas entre griegos y "bárbaros". El discurso presente en las tragedias analizadas es el del poder hegemónico de los helenos conquistadores frente al "otro" vencido.

Los personajes femeninos en Hécuba y las Troyanas experimentan la marginalización desde diferentes espacios; las mujeres se convierten en enemigas, bárbaras y cautivas o en mercancía valiosa para los sacrificios rituales. En la situación de las mujeres de la casa real de Ilión, la dimensión política y social las convierte en botín de guerra. Al desaparecer los varones, ellas pierden el estatus social y su condición de personas, lo que resulta normal en una cultura 
patriarcal como la griega antigua. La objetivación del cuerpo femenino en la guerra es aún mayor que en tiempos de paz, cuando la virginidad es valorada en función del sometimiento y del uso que el enemigo hace de ella, como bien lo expresa el destino de Polixena y Casandra.

Las diferentes subjetividades, desde donde se valora lo femenino, muestran las relaciones de desigualdad y abuso en la construcción de la legitimaciones por medio de la ideología. Los procesos de racionalización naturalizados, a partir de las identidades hegemónicas fijas de un centro masculino, realizan un proceso sistemático de exclusión basado en la materialidad de los cuerpos. Lo femenino como la periferia se convierte en el estereotipo estigmatizado de la mujer como otredad. La diseminación a la vez socava el pensamiento logocéntrico y la construcción del otro como ausencia. La revalorización del "otro" pensado desde las minorías devela esa presencia oculta.

La relectura de los textos literarios desde la marginalidad permite abrir la interpretación de las construcciones de las relaciones sociales basadas en las diferencias. El poder masculino que se ejerce sobre las mujeres impone significaciones de jerarquía y poder disimulados por la ideología. Las conductas que se asumen como normales, producto de la oposición entre lo masculino y lo femenino, se hallan fundamentadas en una construcción social naturalizada y ejercida por medio de la violencia simbólica. La invisibilidad de la violencia simbólica se manifiesta en los esquemas de poder mediante los cuales el dominado se percibe a sí como sometido y acepta al dominador como ente regulador, lo cual es el resultado de la asimilación de las clasificaciones naturalizadas como productos sociales y culturales.

\section{Notas}

1 Las identidades de género son diversas y no necesariamente corresponden al sexo con el que una persona nace. Existe por lo tanto una feminidad y una masculinidad hegemónicas, que se imponen como modelos dominantes, pero existe una variedad de formas de construir y experimentar el género en un cuerpo que puede ser de hombre o de mujer.

2 Desde una perspectiva multidisciplinaria de interpretación diversas autoras, como Beauvoir (2000), Millet (1970), Lerner (1990), Osborne (2001), Buttler (1999), Lagarde (1996), Bernárdez (2001), Gilbert \& Eby (2004), entre otras, señalan que la violencia ejercida contra las mujeres se convierte en una forma de violencia estructural sobre el colectivo femenino.

3 De acuerdo con J. Scott, el género facilita un modo de decodificar la forma cómo las diferentes culturas marcan la diferencia de los sexos para así comprender las diferencias que distinguen el género y el sexo como relaciones significantes de poder. Al designar las relaciones sociales entre los sexos muestra que no hay un mundo de las mujeres separado del mundo de los hombres, mantenido en la ficción de los "estudios de la mujer" donde prevalece la idea de que la experiencia de uno y otro sexo son ajenas. Al respecto ver "El género: una categoría útil para el análisis histórico", www. inau.gub.uy/biblioteca/sexualidad/.../scott.pd 
4

5

Cfr. nota número 2.

Al respecto consultar Sarah Pomeroy, Goddesses, Whores, Wives and Slaves, Women and the city of Athens; Mercedes Madrid (1999), La Misoginia en Grecia, en Feminismo; C. Leduc (1993), ¿Cómo darla en matrimonio?, en Pierre Duby (1993), Historia de las mujeres. La Antigüedad; Dolores Molas (2006), Matrimonio y violencia en la ciudad-Estado griega patriarcal, en La violencia de género en la antigüedad.

Existen leyes desde inicios del siglo IV a.C. contra la violación de las mujeres libres, el adulterio o rapto (Solón XXIII, Plutarco). Los oradores áticos citan las leyes de Dracón "(...) en nuestros días la jurisdicción criminal, tiene expresamente decidido que no se condene por asesinato a quien se cobre tal venganza, si sorprende a un adúltero con su mujer" (Lisias, Defensa por el asesinato de Eratóstenes, 31-34).

En relación con la violencia sexual asociada a la reproducción consultar Dolores Molas (2006), Las violencias contra las mujeres en la poesía griega: de Homero a Eurípides, en La violencia de género en la antigüedad.

Al respecto, la autora cita a Bremmer: "El sacrificio protege a la comunidad en su conjunto de su propia violencia, polarizándola sobre unas víctimas exteriores a ellas. Surge así la figura del chivo expiatorio conocido como la persona de un grupo con el que se liberan las frustraciones y tensiones de los demás individuos. Nos encontramos, por una razón u otra, con víctimas expiatorias que se identifican con personajes al margen de la comunidad". Esta idea se refleja en Jan Bremmer, Scapegoat Rituals in Ancient Greece, HSPh, 87, 1983, 299-320 (303).

Esta situación aparece enfatizada por N. Rabinowitz, en Greek tragedy: A rape Culture (2011): "The slavery that awaits these women is thematic, from first to last $(158,165$ [labor, $\mu$ ó $\chi \theta \omega v$ ], 192, 277, 422, 492, 507, 600, 678, 1271, 1280). "The sexual element is explicitly correlated with labor at line 202: "I shall have greater labors than these, either approaching the beds of the Hellenes (may that night and its spirit disappear) or as a pitiful servant" p.14.

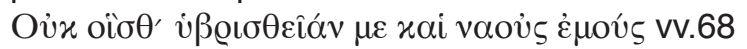

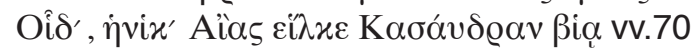

En relación con el mito de Casandra consultar Ruiz de Elvira, Mitología Clásica, 1982.

3 El sacrificio en la tumba del héroe resulta un tanto anómalo en la medida en que los funerales se celebraron en Troya y no en Queroseno. El altar se construye para acceder a las peticiones del phasma del pelida.

4 En qué sentido el sacrificio ocupa el lugar del matrimonio y el degollamiento hace las veces de la desfloración, han sido analizados extensamente por autores como Loraux, Segal y Rabinowitz (2004, pp. 100-101).

\section{Bibliografía}

Aguilar, V. (2002). La violencia simbólica entretejida en la enseñanza del Derecho Penal. Tesis de Maestría. San José: Universidad de Costa Rica.

Aristóteles. (1961). Obras. La política. Barcelona: Aguilar.

Bernárdez, A. (2001). Violencia de género: sociedad, una cuestión de poder. Madrid: Instituto de Investigaciones Feministas.

Bordieu, P. (2000). La dominación masculina. Barcelona: Anagrama. Bordieu, P. y Passeron, J.C. (2004). La reproducción. Madrid: Popular.

Braidotti, R. (2000). Sujetos nómades. Barcelona: Paidós. 
Burkert, W. (2001). Greek Religion. Cambridge: Harvard University Press.

Buttler, J. (2005). Cuerpos que importan, sobre los limites materiales y discursivos del sexo. Buenos Aires: Paidós.

Buttler, J. (2001). El género en disputa. El feminismo y la subversión de la identidad. México: Paidós.

Buttler, J. (1999). Gender Trouble. New York: Routledge.

Easterling, E. (1997). The Cambridge Companion to Greek Tragedy. Cambridge: Cambridge University Press.

Esquines (2002). Discursos. Testimonios y cartas. Madrid: Gredos.

Eurípides (1991). Tragedias I. El Cíclope. Alcestis. Medea. Los Heráclidas. Hipólito. Andrómaca. Hécuba. Madrid: Gredos.

Eurípides (1993). Tragedias II. Suplicantes. Heracles. Ion. Las Troyanas.Electra. Ifigenia entre los Tauros. Madrid: Gredos.

Eurípides (1985). Tragedias III. Helena. Fenicias. Orestes. Ifigenia en Áulide. Bacantes. Reso. Madrid: Gredos.

Finley, M. (1978). El Mundo de Odiseo. México: Fondo de Cultura Económica.

Foucault, M. (1977). Historia de la sexualidad I: La voluntad del saber. Madrid: Siglo Veintiuno.

Fraisse, G. (2002). La controversia de los sexos. Identidad, diferencia, igualdad y libertad. Madrid: Minerva.

Gilbert, P. y Eby, K. (2004). Violence and Gender. (P. Gilbert y K. Eby, Eds.). New Jersey: Pearson Prentice Hall.

Girard, R. (1986). The Scapegoat. Baltimore: The Johns Hopkins University Press. Homero (1991). Iliada. Madrid: Gredos.

Jenofonte (1987). Ciropedia. Madrid: Gredos.

Lagarde, M. (1996). Género y feminismo. Desarrollo humano y democracia. Madrid: Horas y Horas.

Lamas, M. (2000). Usos, dificultades y posibilidades de la categoría de género. In M. Lamas (Ed.), El género la construcción cultural de la diferencia sexual (pp. 327-365). México: PUEG.

Leduc, C. (1993). ¿Cómo darla en matrimonio? en P. Duby y M. Perrot, Historia de las mujeres. La Antigüedad. Madrid: Taurus.

Lerner, G. (1990). La creación del Patriarcado. Barcelona: Crítica.

Lisias (1988). Discursos, Defensa de Eratóstenes (Vol. I). Madrid: Gredos.

Loureaux, N. (1991). Tragic Ways of Killing a Woman. Cambridge: Harvard University Press.

Madrid, M. (1999). La Misoginia en Grecia. Madrid: Cátedra.

McLure, L. (1999). Spoken Like a Woman: Speech and Gender in Atheninan Drama. New Jersey: Princetown University Press.

Millet, K. (1970). Sexual Politics. New York: Doubleday.

Molas, D. (2006). Las violencias contra las mujeres en la poesía griega de Homero a Eurípides. In D. Molas, S. Guerra, E. Huntingford y J. Zaragoza, La violencia de género en la antigüedad. Madrid:Instituto de la Mujer (MTAS).

O.N.U. (1995). Plataforma de Acción de la Declaración de Beijing. Cuarta Conferencia Mundial sobre la Mujer. Beijing: ONU. 
Osborne, R. (2001). La violencia contra las mujeres. Realidad social y políticas públicas. Madrid: UNED .

Peradotto, J., y J. Sullivan (1984). Women in the Ancient World: The Arethusa Papers. New York: State University of New York .

Pinker, S. (2012). Los ángeles que llevamos dentro. El declive de la violencia y sus implicaciones. Barcelona: Paidós.

Pomeroy, S. (1976). Goddesses, Whores, Wives and Slaves. New York: Schoken Books.

Rabinowitz, N. (2011). Greek Tragedy: A rape culture? Retrieved 10, 4, 2014, from http://eugesta.recherche.univ-lille3.fr/revue/pdf/2011/Rabinowitz.pdf

Rodríguez, E. (2004). Animalizar a la víctima: Políxena en la Hécuba de Eurípides. Veleia , 21, 99-107.

Ruiz de Elvira, A. (1982). Mitología Clásica. Madrid: Gredos.

Sagot, M. (1995). Violencia contra las mujeres: el continuum de la muerte. Memoria. Seminario sobre sensibilización de género, leyes y políticas relacionadas con las mujeres. San José: Instituto de Investigaciones Jurídicas, U.C.R.

Said, E. (1990). Orientalismo. Madrid: Libertarias/Prodhufi.

Scodel, R. (1998). Troades, The Captive's Dilemma: Sexual Acquiescence in Euripides Hecuba and Troades. Harvard Studies in Classical Philology , 98, 137-154.

Scott, J. (1990). El género: Una categoría útil para el análisis histórico. In I. S. Nash, Historia y Género: las mujeres en la Europa moderna y contemporánea. Valencia, España: Alfonso el Magnánimo.

Vargas, V. (2002). Los feminismos latinoamericanos en su tránsito al nuevo milenio (Una lectura político personal). In D. Mato, Estudios y otras prácticas intelectuales latinoamericanas en cultura y poder. Caracas: CLASCO. 
